\title{
Semantic priming, prime reportability, and retroactive priming are interdependent
}

\author{
VERONICA J. DARK \\ Iowa State University, Ames, Iowa
}

\begin{abstract}
In two experiments, semantic analysis of prime words was measured in terms of facilitation in naming a semantically related target word. Targets were degraded but gradually clarified until the subject named them. Subjects reported the prime after naming the target. Experiment 1 used semantic associates as primes at a 50-msec prime-target stimulus onset asynchrony (SOA). Experiment 2 used both semantic-associate and identity primes at a 1,000-msec prime-target SOA. Reported primes showed facilitation in both experiments, whereas unreported primes did not. It appears that primes that undergo enough analysis to facilitate target processing are also available for conscious report. However, retroactive priming in both experiments showed that target processing also had an impact on prime reportability. The interdependence of priming and prime reportability disallows a straightforward interpretation of the origin of the facilitation.
\end{abstract}

Recently, there has been much interest in the semantic characteristics of unaware processing (e.g., Balota, 1983; Carr, McCauley, Sperber, \& Parmelee, 1982; Fowler, Wolford, Slade, \& Tassinary, 1981; Hines, Czerwinski, Sawyer, \& Dwyer, 1986; Marcel, 1983a, 1983b). The interest stems in part from the impact of dual-process models of information processing, in which automatic processing is qualitatively distinguished from attentional or controlled processing (e.g., Hoffman, 1979; LaBerge, 1975; Posner \& Snyder, 1975a; Shiffrin \& Schneider, 1977). According to a generic version of the model, when a stimulus occurs in the environment, it is automatically encoded; that is, it produces an internal representation. Automatic processing occurs in parallel, is unlimited in capacity, and does not require effort or intention, but it may be influenced by the physical quality of the stimulus. In contrast, controlled processing is serial, is severely limited in capacity, and requires effort, but it is malleable. It is under intentional control and is required for response initiation in novel situations.

According to the dual-process conceptualization, all stimuli undergo automatic encoding, but because of capacity limitations, not all stimuli receive controlled processing. When several automatically encoded representations are available for controlled processing, only attended (selected) stimuli will actually receive controlled processing. Attention, then, is the process by which controlled processing is enabled. The literature on spatial selective attention is based on the assumption that a stimulus occurring in an unattended location does not receive controlled processing and that measures reflecting

I thank Thomas Carr, Ken den Heyer, Kenneth Foster, William Johnston, and several anonymous reviewers for helpful comments on earlier drafts of this paper. The data presented in this paper were collected while the author was at the University of Utah. Requests for reprints should be sent to Veronica J. Dark, Department of Psychology, Iowa State University, Ames, IA 50011-3180. processing of such stimuli reflect only automatic processes.

Automatic processing and its products are presumed to occur outside of awareness. Controlled processing, however, may lead to awareness of the identity of the stimulus and to memory of the event (e.g., Becklen \& Cervone, 1983; Fisk \& Schneider, 1983). Thus, awareness of stimulus identity has been used as an indication of controlled processing, and an inability to identify a stimulus as an indication of solely automatic processing. The literature on unaware processing is based on the assumption that a stimulus presented under conditions that do not allow its identification has undergone only automatic processing.

Note that in most situations the two criteria provide the same classification of events in terms of the automatic versus controlled processing dichotomy. Under both criteria, identifiable stimuli have undergone controlled processing and stimuli in unattended locations have only been automatically processed. A stimulus presented under data-limited conditions in an attended location, however, may not be identifiable, although it is attended. Processing of an attended, nonidentifiable stimulus will be classified differently under the two criteria. According to the awareness criterion, such a stimulus has only been automatically processed. According to the attention criterion, it may also have undergone some level of controlled processing.

What is the nature of an automatically encoded representation of a stimulus? Although it is generally accepted that automatic encoding occurs for at least some sensory features of a stimulus, there is controversy concerning whether semantic features are automatically encoded (e.g., Johnston \& Heinz, 1978; Keren, 1976). According to many dual-process models (e.g., LaBerge, 1975; Marcel, 1983b; Posner \& Snyder, 1975a; Shiffrin \& Schneider, 1977), the internal representation of a stimu- 
lus generated by automatic encoding includes its semantic features. All stimuli are assumed to make contact with appropriate previously stored semantic information as part of their automatic encoding.

Semantic analysis is usually measured indirectly, via semantic priming (e.g., Fowler et al., 1981; Marcel, 1983a; Posner \& Snyder, 1975b). Semantic priming refers to the facilitation produced by a prime stimulus on the response (usually naming or making a lexical decision) to a semantically related target stimulus. Facilitation is relative to some baseline condition. Semantic priming is assumed to occur when the int ernal representation of the prime causes activation of ass ciatively related concepts (including the target) within : seriantic network (e.g., Collins \& Loftus, 1975; Schva rev sldt \& Meyer, 1973). The issue is whether the semantic components of the representation are activated automatically.

At least two literatures have developed around tests of the presumed automaticity of semantic analysis. The literatures reflect different choices in the characteristic of controlled processing from which semantic analysis is dissociated in order to be classified as automatic. The larger literature uses the attention criterion and is concerned with a dissociation between semantic analysis and selective attention. The smaller literature uses the awareness criterion and is concerned with a dissociation between semantic analysis and awareness of stimulus identity. Dagenbach, Carr, and Kontowicz (1987) similarly described the difference in these literatures as the distinction between success in ignoring a stimulus and failure in attending to a stimulus.

In many studies investigating the dissociability of semantic analysis and selective attention, subjects are directed to attend to stimuli from one set of sources (the relevant sources) and to ignore stimuli from other sources (the irrelevant sources). Evidence of semantic priming by stimuli from irrelevant sources is taken as evidence that semantic analysis is automatic; it occurs even for stimuli not selected to receive controlled processing. The evidence comprising this literature is mixed and has been reviewed many times (e.g., Broadbent, 1982; Holender, 1986; Johnston \& Dark, 1982, 1986; Kahneman \& Treisman, 1984; Shiffrin \& Schneider, 1977). Of interest here is a study recently reported by Johnston and Dark (1985).

Johnston and Dark (1985) examined the priming produced by briefly presented visual stimuli occurring in both relevant and irrelevant locations. The subjects performed an attention task in which word pairs were presented for 67-500 msec before being masked. One word of each pair occurred in a random one of two relevant locations, the other in one of two irrelevant locations. Every few pairs the subject was asked to report the relevant word. Embedded within this attention task was a target-naming task. Severely degraded but gradually clarifying target words were occasionally presented instead of a word pair. The subjects named each target as soon as it could be identified.
Johnston and Dark (1985) contrasted the facilitation in target-naming latency produced by semantically related primes that had immediately preceded the target in relevant versus irrelevant locations. They found priming only from related primes in relevant locations. Even related primes occurring for $67 \mathrm{msec}$ in relevant locations produced facilitation, whereas related primes occurring for $500 \mathrm{msec}$ in irrelevant locations did not. Johnston and Dark concluded that semantic analysis is not dissociable from attention, and thus is not automatic.

Johnston and Dark (1985) were not concerned with a dissociation between stimulus identifiability and semantic analysis, and they had no direct measure of the extent to which subjects were able to identify the primes. However, because the subjects were only about $30 \%$ accurate in identifying other words exposed for $67 \mathrm{msec}$ within the attention task, Johnston and Dark assumed that stimulus identification was not necessary to semantic analysis. Their view was based on the idea that attention to a spatial location is both necessary and sufficient to energize the encoding processes that are conceptualized as being automatic in dual-process theories (e.g., Dark, Johnston, Myles-Worsley, \& Farah, 1985; Hoffman, Nelson, \& Houck, 1983).

The two experiments reported here were designed to determine whether the semantic analysis reflected in Johnston and Dark's (1985) study was automatic in the sense of being dissociable from awareness of stimulus identity even though it required attention. Two general strategies have been used to obtain unawareness of stimulus identity. The first is to determine a detection threshold at which subjects cannot reliably determine that a stimulus has even been presented (e.g., Balota, 1983; Fowler et al., 1981; Marcel, 1983a). The second is to present primes under more moderate data limitations so that some, but not all, of the primes can be identified, and then to conditionalize priming on prime reportability (e.g., Fischler \& Goodman, 1978; Carr et al., 1982). The second strategy was followed in the present study.

Carr et al. (1982) examined the effect of a small set of pattern-masked word and picture primes on the naming latency of a small set of word and picture targets. Some of their primes were presented at a brief but abovethreshold duration and subjects were asked to report these primes after naming the target. A significant priming effect obtained with these primes did not depend on correct report of the related primes. Fischler and Goodman (1978, Experiment 1) also conditionalized priming on prime reportability. They used word primes and word targets in a lexical decision task. In the report condition, primes were presented for $40 \mathrm{msec}$ before being masked. Significant priming under such conditions was obtained only when the subject failed to report the prime.

Both reportability studies suggest that reliable semantic priming should be obtained from attended, unreported primes in Johnston and Dark's (1985) task. However, the overall pattern of semantic priming produced in the two 
studies is not consistent, and there is less support for a prediction about reported primes. Carr et al.,'s (1982) subjects named targets more quickly on trials in which they did not report the prime, but they showed no prime type (related vs. unrelated) $\times$ reportability interaction; that is, all related primes produced equal facilitation in target naming relative to unrelated primes. In contrast, Fischler and Goodman's (1978) subjects produced slower lexical decisions on trials in which they did not identify the prime, and they did show a reportability $\times$ prime type interaction. Lexical decision latencies to targets preceded by reported primes were equal for related and unrelated primes, but unreported related primes showed less slowing of latencies than did unreported unrelated primes.

The discrepancies between the results of Carr et al. (1982) and those of Fischler and Goodman (1978) in semantic priming for reported primes could be due to a number of procedural differences. For example, Carr et al. used a small set of picture and word stimuli with which the subjects were very practiced, whereas Fischler and Goodman used a larger set of word stimuli with which the subjects were unpracticed. Perhaps even more important is that the responses required in the priming tasks were different. Several studies have suggested that naming and lexical-decision responses reflect somewhat different underlying mechanisms (e.g., Balota \& Lorch, 1986; Irwin \& Lupker, 1983; Lorch, Balota, \& Stamm, 1986; Seidenberg, Waters, Sanders, \& Langer, 1984; West \& Stanovich, 1982). The general interpretation is that naming reflects primarily encoding or access to previously stored information about a word, whereas a lexical decision reflects both automatic encoding and some postencoding decision processes (controlled processing). It could be that postencoding processes masked the automatic semantic analysis of reported primes in the study by Fischler and Goodman (1978).

Johnston and Dark's (1985) task requires a targetnaming response, but the target is severely degraded. Target degradation often enhances semantic priming for both naming and lexical decisions and is assumed to affect encoding processes (e.g., Becker \& Killion, 1977; Massaro, Jones, Lipscomb, \& Scholz, 1978; Meyer, Schvaneveldt, \& Ruddy, 1975). On that basis one would predict that Johnston and Dark's task would show a pattern like that obtained by Carr et al. (1982), that is, that reportability would not influence level of priming. On the other hand, the dynamic clarifying aspects of the target stimulus might tap into processes other than encoding, so that the pattern of priming would be closer to that of Fischler and Goodman (1978).

In the two experiments reported here, the reportability procedure was used with the degraded-target naming task. Stimuli were presented singly and in a known location and it was assumed that they would be attended. The stimuli occurred under data-limited conditions that sometimes precluded stimulus identification. Of interest was the extent to which priming depended upon prime identifica- tion. In Experiment 1, semantic priming was examined as a function of prime reportability at a short prime-target stimulus onset asynchrony (SOA). In Experiment 2, priming from both semantic and identity primes at a longer SOA was examined. Reliable priming was obtained only for reported primes in both cases. The data, however, are confounded by retroactive priming effects.

\section{EXPERIMENT 1}

There is some inconsistency in the literature regarding the time course of assumed automatic semantic analysis. Posner and Snyder (1975b) and Neely (1977) suggested that automatic activation effects occur very quickly and are established by $250 \mathrm{msec}$, whereas consciously mediated expectancy effects are more pronounced at around $2 \mathrm{sec}$. Stimuli in both studies were identifiable. In contrast, studies using masked stimuli presented at durations below identification threshold have found that semantic priming is obtained only with prime-target SOAs of around $2 \mathrm{sec}$, and not at SOAs of $250 \mathrm{msec}$ (Fowler et al., 1981) or $350 \mathrm{msec}$ (Balota, 1983). Balota suggested that semantic analysis accrues more slowly with belowthreshold masked stimuli, so that longer SOAs are necessary. Fischler and Goodman (1978), however, found priming for unreported primes at a prime-target SOA of $40 \mathrm{msec}$, and for reportable primes at an SOA of $550 \mathrm{msec}$, but not for primes at a 90 -msec SOA except on trials in which the subject was unable to report the prime. They suggested that the priming tapped with the shorter SOAs was automatic, whereas that tapped with the 550-msec SOA was more associated with controlled processing. Evett and Humphreys (1981) also reported significant semantic priming from unreported primes with a prime-target SOA of approximately $33 \mathrm{msec}$. Finally, Van der Heijden, Hagenarr, and Bloem (1984) suggested that automatic semantic analysis occurs and fades very rapidly.

Experiment 1 was designed to examine whether semantic priming at a short SOA in Johnston and Dark's (1985) target-naming task varies as a function of the subject's ability to report the prime word. On each trial a briefly presented prime was followed almost immediately by a degraded target. The degraded target gradually clarified and the subject's task was to name the target as quickly as possible. After naming the target, the subject attempted to report the prime.

\section{Method}

Subjects and Design. Sixteen students in an introductory psychology class at the University of Utah received course credit for their participation as subjects. All students reported normal or corrected-to-normal vision and fluency in English. Type of prime (related vs. unrelated) was manipulated within subjects. Prime reportability (reported vs. unreported) was a within-subject variable defined by subjects' performance.

Procedure. Stimulus presentation was via a Zenith (Model ZVM121) television screen with a $60-\mathrm{Hz}$ refresh cycle under the 
control of a Terak LSI-11 computer system. The timing software was coordinated with the display hardware so that all display changes began at the same point in the screen refresh cycle. The subject was seated approximately $60 \mathrm{~cm}$ from the television screen in a room with an overhead fluorescent light. All stimuli were presented at the same location in the center of the screen. A single letter was approximately $25 \mathrm{~mm}$ wide $\times 40 \mathrm{~mm}$ high. A six-letter word subtended approximately $.38^{\circ}$ of visual angle vertically and $1.44^{\circ}$ horizontally.

The subject's task was to observe the prime, name the target, and then identify the prime word. Each trial began with a ready signal (two plus signs) presented for $500 \mathrm{msec}$, followed by a 500 msec blank interval. Primes were then presented for $17 \mathrm{msec}$, followed by a 33-msec blank period before the presentation of the target. The target was covered by a random pattern of 300 dots, which made it difficult to see. The dots were removed at an average rate of 1 every $20 \mathrm{msec}$ until the subject responded or until all dots had been removed (a maximum of $6 \mathrm{sec}$ ). When the subject named the target, the vocal response triggered a voice key (Scientific Prototype Model 761G) and the computer recorded the latency of the response and cleared the remaining dots. The target remained on for $500 \mathrm{msec}$ before the report prompt was displayed. The subject had $3 \mathrm{sec}$ in which to report the prime. The instructions encouraged the subject to guess when unsure. An experimenter in an adjoining room scored the accuracy of the subject's vocal responses. There was a I-sec blank interval between trials.

A series of eight practice trials, in which the prime presentation time started out at $500 \mathrm{msec}$ but was gradually reduced to $17 \mathrm{msec}$ by the last trial, familiarized the subject with the task. The subjects were instructed prior to practice that half of the to-be-reported words would be semantically related to the target words. Four of the practice trials included related primes and four included unrelated primes. The subjects were given an opportunity to ask questions after the practice trials; they were reminded that the to-bereported words would be very briefly presented but that they should try their best to identify them. The 60 trials that constituted the experimental sequence were preceded by four buffer trials (two with related primes). The entire session, including debriefing, lasted approximately $15 \mathrm{~min}$.

Stimuli. All stimuli were nouns that were three to nine letters in length. The 60 target words were selected from a set of 210 nouns on which associative and naming norms had previously been collected from 100 students. The norms included clarification naming latencies with both related primes and no prime (baseline). The related prime chosen for each target was the most frequent response given by subjects who were instructed to generate a one-word cue that would make someone else think of the target word. The unrelated prime for each target was a semantically unrelated word with the same length, the same Kucera and Francis (1967) frequency, and the same initial letter as the prime word.

The 60 targets were divided into two sets of 30 words each; the two sets were matched in terms of both the normative primed and baseline naming latencies. One set of 30 words comprised the related-prime targets for a given subject and the other set comprised the unrelated-prime targets. The assignment of word set to priming condition was counterbalanced across subjects. The order of related and unrelated trials was random, with the constraint that there be 5 related and 5 unrelated prime trials in every set of 10 trials. Two orderings of the target words were used equally often to mitigate any idiosyncratic word-sequence effects

\section{Results and Discussion}

Unless otherwise specified, $p<.01$ for all significant differences and $p>.10$ for all nonsignificant differences. The proportion of related primes that were correctly reported $(.737)$ was greater than the proportion of un- related primes that were correctly reported (.492) $[t(15)$ $=7.44, S E=.033$ ]. A similar pattern was obtained by Fischler and Goodman (1978, Experiment 1). It is possible that the difference is attributable to guessing. Subjects were told that the prime was related to the target on half of the trials and they may have guessed a related word on trials on which they were unsure. The guess may in fact have been the actual prime on related trials. In order to test this possibility, the error data of each subject were classed into three categories: no response, response semantically related to target, and response unrelated to the target. The proportion of errors in each of the categories were $.42, .17$, and .41 , respectively, for related prime trials, and $.28, .19$, and .53 for unrelated prime trials. Although there was a difference in the extent to which the various types of errors were made $[F(2,30)=$ $5.24, M S \mathrm{e}=.130]$, there was no interaction between error type and type of prime $[F(2,30)=2.12, M S e=.061]$. It does not appear that the difference in reportability can be attributed to guessing.

A second interpretation of the reportability difference is that it reflects item differences; that is, the related primes as a group were easier to identify than the unrelated primes, in spite of their being matched on length, frequency, and initial letter. A third interpretation is that a form of backward priming was in operation. ${ }^{1}$ Semantic activation from the target may have retroactively increased processing of the related prime words (e.g., Briand, den Heyer, \& Dannenbring, 1987; Jacobson, 1973; Kiger \& Glass, 1983). Data relevant to these two interpretations are reported in Experiment 2.

Naming latencies and accuracies for targets preceded by reported and unreported, related and unrelated primes are presented in the top portion of Table 1, along with the average number of observations on which each latency is based. Naming latencies in this and all other analyses were computed only from correctly identified target words. For each subject, extremely long latencies were replaced with a value two standard deviations away from the subject's mean latency.

An analysis of variance of the latencies with prime reportability and type of prime word as within-subjects factors revealed a main effect of type of prime $[F(1,15)$ $=5.89, M S e=188,454]$, a main effect of prime reportability $[F(1,15)=12.21, M S e=239,191]$, and a reportability $\times$ type of prime interaction $[F(1,15)=9.30, M S e$ $=189,247]$. In general, targets preceded by reportable primes were named more quickly and targets preceded by related primes were named more quickly. Most important, however, was the finding that naming latency was clearly fastest for targets that were preceded by reported related primes. The accuracy data showed a similar pattern.

Targets following reportable primes were named more quickly, regardless of the type of prime. Fischler and Goodman (1978, Experiment 1) found a similar pattern. The pattern can be interpreted in terms of interference in controlled processing if target processing and prime 
Table 1

Mean Target-Identification Latency (in msec), Accuracy (Proportion), and Number of Observations (per Subject) for Reportability and Type of Prime, with Semantic Priming for Each Reportability Level

\begin{tabular}{|c|c|c|c|c|c|c|c|}
\hline \multirow[b]{2}{*}{ Reportability } & \multirow{2}{*}{$\begin{array}{l}\text { Type of } \\
\text { Prime }\end{array}$} & \multicolumn{2}{|c|}{$\begin{array}{l}\text { Naming } \\
\text { Latency }\end{array}$} & \multicolumn{2}{|c|}{$\begin{array}{l}\text { Naming } \\
\text { Accuracy }\end{array}$} & \multirow{2}{*}{$\begin{array}{c}\text { Number of } \\
\text { Observations }\end{array}$} & \multirow{2}{*}{$\begin{array}{l}\text { Semantic } \\
\text { Priming* }\end{array}$} \\
\hline & & $M$ & $S D$ & $M$ & $S D$ & & \\
\hline \multicolumn{8}{|c|}{ Experiment 1: $50-\mathrm{msec} \mathrm{SOA}$} \\
\hline \multirow[t]{2}{*}{ Reported } & Related & 1478 & 645 & .979 & .037 & 21.6 & 592 \\
\hline & Unrelated & 2070 & 1113 & .917 & .135 & 13.9 & \\
\hline \multirow[t]{2}{*}{ Unreported } & Related & 2237 & 1040 & .949 & .078 & 7.2 & -71 \\
\hline & Unrelated & 2166 & 816 & .930 & .054 & 13.9 & \\
\hline \multicolumn{8}{|c|}{ Experiment $2: 1000$-msec SOA } \\
\hline \multicolumn{8}{|c|}{ Semantic Primes } \\
\hline \multirow[t]{2}{*}{ Reported } & Related & 1178 & 521 & .979 & .021 & 20.6 & 419 \\
\hline & Unrelated & 1597 & 753 & .981 & .043 & 9.5 & \\
\hline \multirow[t]{2}{*}{ Unreported } & Related & 1640 & 675 & .935 & .107 & 7.8 & -77 \\
\hline & Unrelated & 1563 & 594 & .943 & .091 & 18.8 & \\
\hline \multicolumn{8}{|c|}{ Identity Primes } \\
\hline \multirow[t]{2}{*}{ Reported } & Related & 923 & 211 & .982 & .038 & 22.3 & 247 \\
\hline & Unrelated & 1170 & 346 & .969 & .053 & 12.3 & \\
\hline \multirow[t]{2}{*}{ Unreported } & Related & 1399 & 527 & .856 & .159 & 5.9 & -54 \\
\hline & Unrelated & 1346 & 398 & .932 & .060 & 15.6 & \\
\hline
\end{tabular}

*Semantic priming $=$ unrelated prime latency - related prime latency.

processing require the same limited-capacity resources. Because subjects were required to identify both types of stimuli, such an interpretation is reasonable. The processing necessary to identify and remember a prime apparently requires less of the limited-capacity resources than does unsuccessful prime processing.

Semantic priming was computed by subtracting the related prime latencies from the corresponding unrelated prime latencies. The facilitative effect of $592 \mathrm{msec}$ produced by reported related primes was reliably above zero $[t(15)=4.06, S E=145]$. The apparent negative priming produced by unreported related primes was not reliably less than zero $(t<1)$. The data strongly suggest that semantic analysis, as measured by semantic priming, and awareness of stimulus identity, as measured by prime reportability, are not dissociable under the procedure used. There is no evidence of semantic analysis of attended primes that cannot be reported after a brief delay. The pattern suggests that the priming obtained from related primes occurring in relevant locations in Johnston and Dark's (1985) study was restricted to instances in which the primes were identified.

The impact of prime reportability on amount of priming in Experiment 1 was not the same as that obtained by either Carr et al. (1982) or Fischler and Goodman (1978, Experiment 1). Carr et al. found priming from reported related primes, as in the present experiment, but Fischler and Goodman did not. Although both Carr et al. and Fischler and Goodman found priming from unreported semantic primes, such priming was not found in the present experiment. The present experiment also replicated Fischler and Goodman's finding of quicker responses to targets following reported primes (related and unrelated); Carr et al. showed the opposite pattern.
There were, of course, large procedural differences among the three studies, but no simple explanation of the three different patterns in terms of either stimulus sets or response tasks suggests itself.

The prime-target SOA of $50 \mathrm{msec}$ was the minimal SOA possible given the available hardware and software. The short SOA was used because of suggestions in the literature that automatic semantic analysis peaks rapidly and then fades (e.g., Fischler \& Goodman, 1978; Van der Heijden et al., 1984). As noted earlier, however, the literature also contains suggestions that semantic priming from undetectable stimuli is obtained only with longer SOAs (e.g., Balota, 1983; Fowler et al., 1981). It is possible that the priming measured in Experiment 1 is not dissociable from stimulus identification because of the temporal parameters. If primes that can be reported are semantically analyzed more quickly than primes that cannot be reported, that analysis may facilitate the naming of the target, whereas the semantic analysis engendered by primes that are not reported accrues too slowly to affect target naming. This possibility was addressed in Experiment 2 by expanding the prime-target $S O A$ to $1 \mathrm{sec}$, the SOA used by Johnston and Dark (1985). In addition, the longer SOA might mitigate the apparent interference between prime processing and target processing revealed in the reportability main effect. Subjects would have more time to complete prime processing before resources were required for target processing.

Experiment 2 also included an immediate identity-prime group in which the related prime was identical to the target. From an activation viewpoint, using the actual target word as the related prime should allow maximal activation of the internal representation of the target by the prime. In addition to semantic activation, an identity prime 
can also provide physical and graphemic priming. Evett and Humphreys (1981), for example, found more facilitation from immediate identity primes than from immediate semantic primes under data-limited conditions. If there is low-level processing of unreported related primes, it may be more easily detected in an identity-prime group.

Finally, a control group was included to determine whether item differences or backward priming was responsible for the higher reportability of related primes than unrelated primes in Experiment 1. Control-group subjects only identified the prime.

\section{EXPERIMENT 2}

\section{Method}

Subjects and Design. Forty-eight students from an introductory psychology class at the University of Utah received course credit for participating as subjects. All students reported normal or corrected-to-normal vision and fluency in English. No subject had participated in Experiment 1. Sixteen subjects each were assigned to the semantic-prime group, the identity-prime group, and the control group. Type of prime (related vs. unrelated) was manipulated within subjects. Prime reportability (reported vs. unreported) was a within-subjects factor determined by subjects' performance.

Procedure. The equipment was as described for Experiment 1. The sequence of events constituting a trial for the semantic-prime and identity-prime groups was similar to that of Experiment 1, except that a mask of nine Xs and a relatively long blank interval occurred between the prime and target. The events were as follows: ready signal $(500 \mathrm{msec}+500 \mathrm{msec}$ blank $)$, prime $(17 \mathrm{msec}+$ 17 msec blank), mask of nine Xs (33 msec), 933-msec blank period, degraded but clarifying target (up to $6 \mathrm{sec}$ ), clear target $(500 \mathrm{msec}$ +500 msec blank), and finally the report prompt ( $3 \mathrm{sec}+1 \mathrm{sec}$ blank). The prime-target SOA was $1 \mathrm{sec}$. A control group trial began like a priming trial but no targets were presented. Rather, the mask of nine Xs was followed, after $933 \mathrm{msec}$, by the report prompt. The subject's task was simply to identify the prime.

Subjects were presented eight practice trials in which prime duration began at $500 \mathrm{msec}$ but decreased to $17 \mathrm{msec}$. Subjects in both priming groups were informed that half of the trials would contain to-be-reported words related to the target. The entire session, including debriefing, lasted approximately $15 \mathrm{~min}$.

Stimuli. Stimuli for the semantic-prime group were the same four sequences of 60 prime-target pairs described in Experiment 1. The actual target, rather than a semantic associate, was used as the related prime for the identity-prime group. Each control-group subject saw the prime portion of the displays presented to a yoked subject in the semantic-prime group

\section{Results and Discussion}

Target naming. Naming latencies and accuracies for targets preceded by reported and unreported, related and unrelated primes are presented for each prime group in the lower portion of Table 1 , along with the average number of observations upon which each latency is based. An analysis of variance of the latencies with prime group as a between-subjects factor and prime reportability and type of prime as within-subjects factors revealed a main effect of type of prime $[F(1,30)=12.76, M S e=44,735]$, a main effect of prime reportability $[F(1,30)=25.80$, $M S e=90,232]$, and a reportability $\times$ type of prime interaction $[F(1,15)=25.06, M S e=50,695]$. There was no reliable effect of group $[F(1,30)=2.78, M S e=$ $937,959]$, and there were no significant interactions in- volving group. As in Experiment 1, targets preceded by related primes and targets preceded by reported primes were named more quickly, but targets preceded by reported related primes were particularly fast. The accuracy means showed only an effect of prime reportability.

Subjects were faster at naming the targets with the longer SOA in Experiment 2 than in Experiment 1. Carr et al. (1982) also found a decrease in naming latency as SOA increased, as have several others (e.g., de Groot, 1984; den Heyer, Taylor, \& Abate, 1986; Lorch, 1982). The longer prime-target SOA apparently allowed more complete analysis of the prime before the target was even presented, resulting in less competition for limitedcapacity resources. In spite of this, however, reportability continued to directly impact target naming latency. Unsuccessful prime processing interfered more with target naming than did successful prime processing for both related and unrelated primes. It appears that remembering an identified prime required less resources than did the processing characterizing the unsuccessful trials.

Semantic priming was computed by subtracting the related prime latencies from the unrelated prime latencies for each reportability value. The $419-\mathrm{msec}$ facilitation produced by reported related primes in the semanticprime group was reliably greater than zero $[t(15)=4.71$, $S E=89]$, as was the facilitation of $246 \mathrm{msec}$ in the identity-prime group $[t(15)=3.61, S E=68]$. The apparent negative priming produced by unreported related primes was not reliably different from zero in either the semantic-prime group $[t(15)=1.08, S E=71]$ or the identity-prime group $(t<1)$. The pattern of priming was similar to that obtained in Experiment 1. There is no evidence for semantic analysis of related primes that the subject was unable to identify even when the prime and target were physically identical.

Evett and Humphreys (1981) and Forster and Davis (1984) both reported priming from identity primes of which the subject was unaware. Evett and Humphreys sequentially presented two words for $33 \mathrm{msec}$ each between a premask and a postmask. The subjects were instructed to report what they saw. The subjects almost never reported the first word, but their report of the second word was facilitated if the first word was either a lowercase instance of the second word or a semantic associate of the second word. The lowercase identity prime increased accuracy more than did the semantic associate. The present data reveal no difference in the levels of facilitation produced by semantic and physically identical related primes that immediately precede the target. There is also no evidence of priming produced by unreported related primes of either type.

Carr and Dagenbach (1986; Dagenbach et al., 1987) suggested that semantic inhibition can produce reliable negative priming in situations in which subjects unsuccessfully attempt to access an area of semantic memory. To more sensitively test whether the apparent negative priming found for unreported related primes in Experiments 1 and 2 might be an example of this phenomenon, 
the data were combined. The mean of $-68 \mathrm{msec}$ was not reliably below zero $[t(47)=1.05, S E=65]$.

Neither Experiment 1 nor Experiment 2 produced semantic priming from unreported related primes. Using the same priming task, Johnston and Dark (1985) found no evidence of semantic analysis of related primes presented for longer periods in unattended locations. Johnston and Dark concluded that semantic analysis is not an automatic process because it requires attention. The present data suggest the stronger statement that the semantic analysis tapped by the clarification task depends not only upon attention but upon enough controlled processing to allow prime identification. It is not an automatic process, either by the attention criterion or by the awareness criterion.

Prime identification. For purposes of analysis, the sets of words comprising the related and unrelated primes for subjects in the semantic group were treated as related and unrelated primes for the control group. The proportions of correctly reported related and unrelated primes for the identity-prime, semantic-prime, and control groups are shown in Table 2 . An analysis of variance with group and type of prime as factors showed a main effect of type of prime $[F(1,45)=63.23]$ and a group $\times$ type of prime interaction $[F(2,45)=15.53]$ ( $M S \mathrm{e}=.0225$ for both), but no main effect of group $[F(2,45)=1.00, M S e=$ .0754].

Both priming groups in Experiment 2 showed a pattern similar to that in Experiment 1: related primes were reported at a higher rate than unrelated primes. The control group was included to determine whether differences in reportability between related and unrelated primes were the result of item differences or of processes occurring during the priming trials. Control-group subjects showed equal report of both sets of words, confirming that the two sets were well-matched and that the difference in reportability was not a function of item differences.

A Newman-Keuls analysis revealed that report of unrelated primes was reliably depressed for the semantic group compared to the control group, and that report of related primes was reliably enhanced. The identity group's report of unrelated primes did not differ from that of either the semantic group or the control group. Although the identity group's related primes consisted of a different set of words than that of the other two groups, report of related primes was compared across groups. The identity group's report of related primes was reliably greater

Table 2

Proportion of Correctly Reported Related and Unrelated Primes for Each Group

\begin{tabular}{clll}
\hline Group & Type of Prime & $M$ & SD \\
\hline Control & Related & .512 & .240 \\
& Unrelated & .507 & .248 \\
Semantic & Related & .714 & .173 \\
& Unrelated & .328 & .246 \\
\multirow{3}{*}{ Identity } & Related & .769 & .145 \\
& Unrelated & .429 & .252 \\
\hline
\end{tabular}

than that of the control group, but not different from that of the semantic group. The reportability pattern suggests the operation of two factors in the priming groups: forgetting and retroactive priming.

Holender (1986) argued that delayed reports such as those used in the reportability paradigm may not accurately reflect whether a stimulus was originally identified, because the subject can forget the stimulus during the retention interval. Because subjects in Carr et al.'s (1982) study were always able to report the prime when prime report was their only task, Holender attributed the results showing equal priming for reported and unreported primes to forgetting of the prime rather than to nonidentification of the prime. The present data confirm that forgetting does occur, at least for unrelated primes, and provide a basis for reconciliation between the pattern of priming obtained by Carr et al. and the pattern obtained in the present experiments. Subjects in the control group of Experiment 2 could identify only half of the primes when that was their only task. By inference, not all of the unreported primes in the priming groups were identified and then forgotten, as may have been the case in Carr et al.'s study. The difference in priming from unreported related primes in Carr et al.'s study and the present experiments may be due not to the use of different tasks, but to differences in the level of controlled processing originally received by the unreported related primes.

The data of Experiment 2 also suggest that a retroactive priming process may mitigate forgetting when the prime is related to the target. It appears that the semantic analysis of the target maintains or boosts activation of the internal representation of a related prime, resulting in a greater likelihood of reporting the prime. Fischler and Goodman (1978, Experiment 1) reported a similar pattern: related primes were more likely to be reported than were unrelated primes. Carr et al. (1982) did not report the proportion of identified related and unrelated primes.

The occurrence of retroactive priming allows alternative explanations of the relationship between reportability and semantic priming. Targets presented after reported related primes may be more quickly identified because their representations receive activation from semantic analysis of the related primes, or because quickly identified targets produce more activation of the representations of related stimuli, so that the related prime's representation becomes (or remains) reportable, or both. Because the prime and target cannot be temporally separated (e.g., Dannenbring \& Briand, 1982; Henderson, Wallis, \& Knight, 1984), there appears to be no easy way to tease apart the two processes.

\section{GENERAL DISCUSSION}

The phenomenon of retroactive priming complicates the interpretation of these and other data in relation to an important question: What sort of processes are reflected in semantic priming measures? The use of semantic priming as a measure of semantic analysis of the prime is based 
upon the assumption that prime processing can affect subsequent target processing (e.g., Balota, 1983; Carr et al., 1982; Fischler \& Goodman, 1978; Fowler et al., 1981; Marcel, 1983a). Although the interpretation of semantic priming as reflecting primarily automatic semantic analysis is not always clear because factors associated with controlled processing are known to affect semantic priming (e.g., den Heyer, 1986; den Heyer, Briand, \& Dannenbring, 1983; den Heyer, Briand, \& Smith, 1985; Henik, Friedrich, \& Kellogg, 1983; Hoffman \& MacMillon, 1985; Seidenberg et al., 1984; Smith, Theodor, \& Franklin, 1983; Tweedy, Lapinski, \& Schvaneveldt, 1977), it is usually assumed that any impact of controlled processing is in addition to the forward influence of the related prime on the target. The present data call into question this last assumption. It appears that semantic analysis of the related prime is not itself independent of target processing. Semantic priming is a measuring instrument that influences what it is measuring. Some other kind of indirect measurement is needed if the semantic properties of early automatic encoding are to be explored (e.g., Avant \& Thieman, 1985).

The priming task used in the present experiments is not the standard lexical decision or naming task. It produces longer response times and may therefore be criticized as reflecting processes other than automatic semantic analysis. The present data cannot rule out the possibility that all stimuli undergo an extremely early and rapidly decaying form of automatic stimulus encoding that includes a semantic component (e.g., Van der Heijden et al., 1984). The data do, however, point out a major problem with using a semantic priming task of any kind to investigate the nature of such an early, automatic encoding stage: target processing may cause changes in the representation of the prime. In situations in which a related target occurs immediately after a prime, the processing of the target may be facilitated by the automatically encoded prime representation. However, retroactive priming from the target to the related prime may also occur. Processing of the target may strengthen activation of a relatively weak representation of the prime, which can then further influence activation of the target. Thus, there is no clear interpretation of the origin of the facilitation or, by inference, of the nature of the automatically encoded prime representation.

Briand et al. (1987) recently made a similar point using a standard target-naming task combined with a lexical decision about the prime. Their subjects made the lexical decision about briefly presented, masked primes immediately after they had named a clear target. The subjects were more accurate and more confident in their lexical decisions about related primes than in those about unrelated primes. In addition, facilitation in target-naming latency was produced only by related primes that had been correctly classified as words rather than nonwords. Briand et al. described prime processing and target processing as synergistic.
Although they did not measure identifiability of the stimuli for which the lexical decisions were obtained, Briand et al. (1987) suggested that retroactive priming may enhance awareness of the identity of the related primes. The data from Experiments 1 and 2 of the present study confirm their hypothesis. The phenomenon of retroactive priming provides a mechanism by which a subject may, in fact, be more aware of the identity of stimuli on priming trials than on threshold-setting trials in subliminal priming studies (e.g., Balota, 1983; Fowler et al., 1981; Marcel, 1983a). Just as Purcell, Stewart, and Stanovich (1983) suggested that the light levels need to be matched between threshold trials and priming trials in such studies, the present data and those of Briand et al. (1987) suggest that semantic context must also be matched.

Prime reportability interacted with type of prime in Experiments 1 and 2 so that semantic priming was obtained only for reported primes. Regardless of the nature of the processes reflected in the priming measure, they were evident only on trials on which the subject was able to report the related prime. The interdependence between semantic priming and prime reportability challenges interpretations of dual-process theory in which complex, semantic processing occurs for all stimuli whether or not the subject is aware of the identity of the stimuli. The suggestion is not that the subject is aware of all semantic processing, but that the semantic processing underlying priming is not dissociable from the processing that allows identification of the prime. This distinction has also been described by den Heyer et al. (1983) as the difference between automatic processing of a prime and the automatic effect of the prime once it has been processed. Semantic priming may, in fact, reflect automatic activation of which the subject is not aware, but that activation is produced by stimuli of which the subject is aware. For this reason, semantic activation may be better described within the dual-process conceptualization as what Shiffrin and Schneider (1977) called a veiled control process, rather than as an automatic process.

Note that the present data would also support a oneprocess conceptualization of stimulus processing in which processing is described as activation within a complex interacting network of nodes (e.g., Johnston, 1980; McClelland \& Rumelhart, 1985). Stimulus representations that receive high-level activation from external sources or from the internal structure of the network can be identified and can also produce activation of related representations. Representations that do not receive enough activation to be identified do not influence the activity of other representations. Thus, aware and unaware processing would differ in degree, not in kind.

\section{REFERENCES}

Avant, L. L., \& Thieman, A. A. (1985). On visual access to letter case and lexical/semantic information. Memory \& Cognition, 13, $392-404$.

Balota, D. A. (1983), Automatic semantic activation and episodic 
memory encoding. Journal of Verbal Learning \& Verbal Behavior, 22, 88-104.

BALOTA, D. A., \& LORCH, R. F., JR. (1986). Depth of automatic spreading activation: Mediated priming effects in pronunciation but not in lexical decision. Joumal of Experimental Psychology: Learning, Memory, \& Cognition, 12, 336-345.

BECKER, C. A., \& KLLION, T. H. (1977). Interaction of visual and cognitive effects in word recognition. Journal of Experimental Psychology: Human Perception \& Performance, 3, 389-401.

Becklen, R., \& Cervone, D. (1983). Selective looking and the noticing of unexpected events. Memory \& Cognition, 11, 601-608.

Briand, K., DEN HeYer, K., \& Dannenbring, G. L. (1987). Retroactive priming in a lexical decision task. Manuscript submitted for publication.

BroadBENT, D. E. (1982). Task combination and selective intake of information. Acta Psychologica, 50, 253-290.

CARR, T. H., DAGENBACH, D. (1986). Now you see it, now you don't: Relations between semantic activation and awareness. Behavioral \& Brain Sciences, 9, 26-27.

Carr, T. H., McCauley, C., Sperber, R. D., \& Parmelee, C. M. (1982). Words, pictures, and priming: On semantic activation, conscious identification, and automaticity of information processing. Journal of Experimental Psychology: Human Perception \& Performance, 8, 757-777.

Coluins, A. M., \& LofTUs, E. F. (1975). A spreading activation theory of semantic processing. Psychological Review, 82, 407-428.

Dagenbach, D., CarR, T. H., KontowicZ, A. L. (1987). Taskinduced strategies and subthreshold priming: Conscious influences on unconscious perception. Manuscript submitted for publication.

Dannenbring, G. L., \& BRIAND, K. (1982). Semantic priming and the word repetition effect in a lexical decision task. Canadian Journal of Psychology, 36, 435-444.

Dark, V. J., Johnston, W. A., Myles-Worsley, M., Farah, M. J. (1985). Levels of selection and capacity limits. Joumal of Experimental Psychology: General, 114, 472-497.

DE Groot, A. M. B. (1984). Primed lexical decision: Combined effects of the proportion of related prime-target pairs and the stimulusonset asynchrony of prime and target. Quarterly Journal of Experimental Psychology, 36A, 253-280.

DEN HEYER, K. (1986). Manipulating attention-induced priming in a lexical decision task by means of repeated prime-target presentations. Joumal of Memory \& Language, 25, 19-42.

den Heyer, K., Briand, K., \& Dannenbring, G. L. (1983). Strategic factors in a lexical decision task: Evidence for automatic and attention-driven processes. Memory \& Cognition, 11, 374-381.

den Heyer, K., Briand, K., SMITH, L. (1985). Automatic and strategic effects in semantic priming: An examination of Becker's verification model. Memory \& Cognition, 13, 228-232.

DEN Heyer, K., TAYLOR, M. A., \& ABATE, A. (1986). On the nature of neutral primes in a lexical decision task. Psychological Research, 48, 161-168.

EveTt, L. J., \& Humphreys, G. W. (1981). The use of abstract graphemic information in lexical access. Quarterly Journal of $E x$ perimental Psychology, 33A, 325-350.

FisCHLER, I., \& GOODMAN, G. O. (1978). Latency of associated activation in memory. Journal of Experimental Psychology: Human Perception \& Performance, 4, 455-470.

FISK, A. D., \& SCHNEIDER, W. (1983). Category and word search: Generalizing search principles to complex processing. Journal of Experimental Psychology: Learning, Memory, \& Cognition, 9, 177-195.

FORSTER, K. I., \& DA VIS, C. (1984). Repetition priming and frequency attenuation in lexical access. Journal of Experimental Psychology: Learning, Memory, \& Cognition, 10, 680-698.

Fowler, C. A., Wolford, G., Slade, R., \& Tassinary, L. (1981). Lexical access with and without awareness. Journal of Experimental Psychology: General, 110, 341-362.

Henderson, R., Wallus, J., Knight, D. (1984). Morphemic structure and lexical access. In H. Bouma \& D. G. Bouwhuis (Eds.), Attention and performance $X$ : Control of language processes (pp. 211226). London: Erlbaum.
Henik, A., Friedrich, F. J., \& KellogG, W. A. (1983). The dependence of semantic relatedness effects upon prime processing. Memory \& Cognition, 11, 366-373.

Hines, D., Czerwinski, M., Sawyer, P. K., \& DWyer, M. (1986). Automatic semantic priming: Effect of category exemplar level and word association level. Journal of Experimental Psychology: Human Perception \& Performance, 12, 370-379.

Hoffman, J. E. (1979). A two-stage model of visual search. Perception \& Psychophysics, 25, 319-327.

Hoffman, J. E., \& MacMillon, F. W. (1985). Is semantic priming automatic? In M. I. Posner \& O. S. M. Marin (Eds.), Attention and performance XI: Mechanisms of attention (pp. 585-599). Hillsdale, NJ: Erlbaum.

Hoffman, J. E., Nelson, B., \& Houck, M. R. (1983). The role of attentional resources in automatic detection. Cognitive Psychology, $15,379-410$.

HoleNDER, D. (1986). Semantic activation without conscious identification in dichotic listening, parafoveal vision, and visual masking: A survey and appraisal. Behavioral \& Brain Sciences, 9, 1-66.

IRWIN, D. I., LuPKER, S. J. (1983). Semantic priming of pictures and words: A levels of processing approach. Journal of Verbal Leaming \& Verbal Behavior, 22, 45-60.

JACOBSON, J. Z. (1973). Effects of association upon masking and reading latency. Canadian Joumal of Psychology, 27, 58-69.

JOHNSTON, W. A. (1980). A mechanistic theory of attention. Unpublished manuscript.

Johnston, W. A., \& DARK, V. J. (1982). In defense of intraperceptual theories of attention. Joumal of Experimental Psychology: Human Perception \& Performance, 8, 407-421.

JoHnston, W. A., \& DARK, V. J. (1985). Dissociable domains of selective processing. In M. I. Posner \& O. S. M. Marin (Eds.), Attention and performance XI: Mechanisms of attention (pp. 567-583). Hillsdale, NJ: Erlbaum.

Johnston, W. A., \& DARK, V. J. (1986). Selective attention. Annual Review of Psychology, 37, 43-75.

Johnston, W. A., Heinz, S. P. (1978). Flexibility and capacity demands of attention. Journal of Experimental Psychology: General, $107,420-435$.

Kahneman, D., Treisman, A. (1984). Changing views of attention and automaticity. In R. Parasuraman \& R. Davis (Eds.), Varieties of attention (pp. 29-61). Orlando, FL: Academic Press.

KEREN, G. (1976). Some consideration of two alleged kinds of selective attention. Journal of Experimental Psychology: General, 105, 349-374.

KIger, J. I., \& Glass, A. L. (1983). The facilitation of lexical decisions by a prime occurring after the target. Memory \& Cognition, 11, 356-365.

Koriat, A. (1981). Semantic facilitation in lexical decision as a function of prime-target association. Memory \& Cognition, 9, 587-598.

Kučera, H., Francis, W. N. (1967). Computational analysis of present-day American English. Providence: Brown University Press.

LABERGE, D. (1975). Acquisition of automatic processing in perceptual and associative learning. In P. M. A. Rabbitt \& S. Dornic (Eds.), Attention and performance V (pp. 50-64). New York: Academic Press.

LoRCH, R. F., JR. (1982). Priming and search processes in semantic memory: A test of three models of spreading activation. Journal of Verbal Leaming \& Verbal Behavior, 21, 468-492.

LoRCh, R. F., JR., BALota, D. A., \& Stamm, E. G. (1986). Locus of inhibition effects in the priming of lexical decisions: Pre- or postlexical access? Memory \& Cognition, 14, 95-103.

MARCEL, A. J. (1983a). Conscious and unconscious perception: Experiments on visual masking and word recognition. Cognitive Psychology, 15, 197-237.

MARCEL, A. J. (1983b). Conscious and unconscious perception: An approach to the relations between phenomenal experience and perceptual processes. Cognitive Psychology, 15, 238-300.

Massaro, D. W., Jones, R. D., Lipscom8, C., \& SCholz, R. (1978). Role of prior knowledge on naming and lexical decisions with good and poor stimulus information. Journal of Experimental Psychology: Human Learning \& Memory, 4, 498-512. 
MCClelland, J. L., \& Rumelhart, D. E. (1985). Distributed memory and the representation of general and specific information. Journal of Experimental Psychology: General, 114, 159-188.

MEYer, D. E., SchVaneveldt, R. W., \& Ruddy, M. G. (1975). Loci of contextual effects on visual word-recognition. In P. M. A. Rabbitt \& S. Domic (Eds.), Attention and performance V (pp. 98-118). New York: Academic Press.

NeELY, J. H. (1977). Semantic priming and retrieval from lexical memory: Roles of inhibitionless spreading activation and limitedcapacity attention. Journal of Experimental Psychology: General, 106, 226-254.

Posner, M. I., \& SNyder, C. R. R. (1975a). Attention and cognitive control. In R. L. Solso (Ed.), Information processing and cognition: The Loyola Symposium (pp. 55-85). Hillsdale, NJ: Erlbaum.

Posner, M. I., \& SNyder, C. R. R. (1975b). Facilitation and inhibition in the processing of signals. In P. M. A. Rabbitt \& S. Dornic (Eds.), Attention and performance V (pp. 669-682). New York: Academic Press.

Purcell, D. G., Stewart, A. L., \& Stanovich, K. E. (1983). Another look at semantic priming without awareness. Perception \& Psychophysics, 34, 65-71.

Schvaneveldi, R. W., \& Meyer, D. E. (1973). Retrieval and comparison processes in semantic memory. In S. Kornblum (Ed.), Attention and performance $I V$ (pp. 395-409). New York: Academic Press.

Seidennerg, M. S., Waters, G. S., Sanders, M., \& Langer, P. (1984). Pre- and postlexical loci of contextual effects on word recognition. Memory \& Cognition, 12, 315-328.

Shiffrin, R. M., SCHNEIDER, W. (1977). Controlled and automatic human information processing: II. Perceptual learning, automatic attending, and a general theory. Psychological Review, 84, 127-190.
Smith, M. C., Theodor, L., \& FrankLin, P. E. (1983). The relationship between contextual facilitation and depth of processing. Journal of Experimental Psychology: Learning, Memory, \& Cognition, 9, 697-712.

Tweedy, J. R., Lapinski, R. H., \& SchVaneveldt, R. W. (1977). Semantic-context effects on word recognition: Influence of varying the proportion of items presented in an appropriate context. Memory \& Cognition, 5, 84-89.

Van der Heuden, A. H. C., HagenarR, R., \& Bloem, W. (1984). Two stages in postcategorical filtering and selection. Memory \& Cognition, 12, 458-469.

WEST, R. F., \& STANOvich, K. E. (1982). Source of inhibition in experiments on the effect of sentence context on word recognition. Journal of Experimental Psychology: Leaming. Memory, \& Cognition, 8, 385-399.

\section{NOTE}

1. Backward priming is a term that has been used to refer both to the temporal ordering of the stimuli, that is, instances in which a semantically related word occurring after another word facilitates the response to the first word (e.g., Jacobson, 1973; Kiger \& Glass, 1983), and to the assumed direction of activation over an associative link (e.g., Koriat, 1981). Briand et al. (1987) suggested the term retroactive priming as more descriptive of the former, and this term will be used hereafter.

(Manuscript received December 31, 1986; revision accepted for publication December 11, 1987.) 